\title{
Sperm Agglutination, Sperm Shaky Head Movement and Sperm-Cervical Interaction Tests could be enough for Diagnosis of Immunological Infertility?
}

\author{
Ahmed K Allow ${ }^{1 *}$, Sadek SM Abdulmogny A ${ }^{2}$, Bracamonte Maryam ${ }^{3}$ and Belqees A Alaw ${ }^{4}$ \\ ${ }^{1}$ Department of Basic Medical Science, International Islamic University, Malaysia \\ ${ }^{2}$ Department of Physiology, Sana'a University, Yemen \\ ${ }^{3}$ Allow IVF Center, Yemen \\ ${ }^{4}$ Department of Oral Biology, UniversiPutri Malaysia, Malaysia \\ Submission: February 05, 2017; Published: March 08, 2017 \\ *Corresponding author: Ahmed Kaid Naji Allow, Department of Basic Medical Science, Kulliyyah of Medicine, International Islamic University, \\ Malaysia,Email: ivf2007@gmail.com
}

\begin{abstract}
Objectives of this work were: 1) to investigate the infertile patients with immunological infertility through the assessment of their results of semen analysis, sperm agglutination (SA) and sperm shaky head movement (SSM). 2) Study the recovery of sperm-cervical mucus interaction in infertile couples was studied. Patients and Methods: two hundred and eight infertile couples were investigated. Female factor of infertility was normal. According to the percentage of SA patients were divided into 2 groups. Patients also were studied according their age factor to three age groups. The sperm-cervical mucus interaction was studied. Results: The seminal fluid infection was recorded as the higher percentage of causes of infertility in patients group-I in compared to patients in group-II.SA was noted significantly ( $\mathrm{P}=0.002)$ higher in age group 2 (30-40 years) compared to age group 1 and 3 . Percentage of SSM was significantly, $P=0.03$, in the age group 3 compared to age group 2. The percentage of motility of sperm recovery was significantly better in age G2 compared to age G1 and 3. At the same time the heist sperm concentration recovery as well as sperm agglutination were significantly $(\mathrm{p}=0.02)$ higher in age group 2 . Conclusion: $60 \%$ of causes of immunological infertility mainly associated with sterile seminal fluid infection. The SA and SSM should be involved as routine tests to diagnose of immunological infertility. Percentage of SSM was increased by an increment in the age of patients.
\end{abstract}

Keywords: Sperm agglutination; Immunological infertility; Yemeni infertile couples

\section{Introduction}

Conception is normally achieved within twelve months in $80-85 \%$ of couples who use no contraceptive measures and persons presenting after this time should therefore be regarded as possibly infertile and should be evaluated. Immunologic factors are considered as important causes of infertility [1]. One of the immunologic factors proposed for infertility (20\% of all causes of infertility) is presence of SA, ASAs in sera of infertile men and women, seminal plasma, cervical mucus, and follicular fluids $[1,2]$.

Rumke [3], Wilson [4] were the first to report the presence of antisperm antibodies (ASAs) in infertile men. Now ASAs are defined as immunoglobulines (Ig) of the IgG, IgA and/ or IgM class that are located to various sites of the spermatozoa (head, tail, midpiece or combination thereof) [2]. The incidence of sperm agglutination due to autoimmunity in infertile couples is $9-36 \%$ in contrast to $0.9-4 \%$ in the fertile population. The incidence of detection of ASAs in the fertile male is $8-21 \%$ and in the female $6-23 \%$. Immunological cause may contribute to $5-15 \%$ of the male infertility factors [5]. It was reported that immunologic infertility is possible if more than $50 \%$ sperm are bound to IgG or IgA antibodies and it may be suspected if more than $10 \%$ spermatozoa are antibody bound. An un-symptomatic immune response to certain tissues of the reproductive system can cause infertility $[5,6]$.

Furthermore, presence of ASAs in the female reproductive tract can prevent their motility through the female reproductive tract or prevent the process of fertilization $[2,7]$ and decrease 
the cleavage rate in patients with high titer of ASAs following IVF [8].

Finally, all these immunological infertility factors that lead to the development of SA and ASAs among Yemeni infertile patients are prevailing and are yet to be evaluated, thus enabling us to take the necessary measures of prevention and treatment. On the other side, SA and ASAs lab tests are still subjects of debate and there is a lack of consensus on clinical consequences of ASAs. We hope our present study will define the importance of SA and SSM screening in the process of diagnosis of immunological infertility and their relationship with infertility by involving large number of infertile patients with high percentage of SA, and high ASAs in their semen and sera and long duration of this study. Furthermore in all Yemeni labs (governmental and private) the seminal fluid reports do not include percentage and types of SA, percentage of SSM and ASAs tests as a routine test for diagnosis of immunological infertility. All these problems give us strong impetus to study them thoroughly. So, the present study is aimed to:

a. Investigate the infertile patients with immunological infertility through the assessment of their results of semen analysis, SA,SSM and sperm-cervical interaction.

b. The necessity of including fresh micro-slide SA and SSM lab technique as a routine clinical lab tests for diagnosis of immunological infertility.

\section{Patient and Methods}

\section{Patients}

Two hundred and eight infertile couples involved in this study. Complete physical, medical, and infertility data were documented and diagnosed as infertile cases with positive sperm agglutination and sperm shaky head movement. Their sex and thyroid hormonal profiles and prolactin were within the normal values. There was no history of administration of glucocorticoids at least for 3 months prior to participation in the present study and seminal fluid culture and sensitivity was negative for pathogenic bacterial growth. They were inspected for any history of testicular trauma, mumps, orchitis, testicular torsions, varicocele, cryptorchidism, surgical intervention, sterile seminal fluid infection. All husbands have positive anti-sperm antibodies (ASA) in own sera and seminal fluid. The institutional review board at Colleague of Medicine and Health Science, Sana'a University approved the protocol, and couples gave written informed consent. All wives were normally reproductive and fertile. According to the percentage of agglutination, patients was divided into 2 groups (Group $-1<10 \%$ and group $2>$ or $=10 \%$ ). According to age factor, patients were divided into 3 groups. Group 1 less than 30, group 2: 31-40 and group 3 more than 40 years in age. All these groups were compared to normal fertile men. The sperm agglutination and sperm shaky head were the main factors. Intrauterine insemination was performed for all couples.

\section{Spermogram and its evaluation}

Written informed consent was obtained from all participants after recruitment. Semen samples were collected by masturbation at the site of our center, after the men had been asked to abstain from ejaculation for at least 48 hours before semen was collected. All semen analyses were performed manually within one hour after the sample was collected and included measurements of the volume of the ejaculate and determinations of the sperm concentration and the percentage of sperm motility, shaky head movement, agglutination and morphology. Tow-three semen specimens were obtained from each man who was involved in the present study. The number of days between the specimen collections was from 25-42 days. The mean values for each semen sample were calculated in studied by slide method. Semen fluid analyses were performed in our external out-patient labaccording the guidelines of the World Health Organization [9].

\section{Sperm agglutination}

Agglutination of spermatozoa means that motile spermatozoa stick to each other - head to head agglutination, tail to tailor in a mixed way, e. g. med-piece to tail. The adherence either of immotile spermatozoa to each other or of motile spermatozoa to mucus threads, cells other than spermatozoa, or debris is considered to be nonspecific agglutination. The specimen was observed for sperm agglutination by preparing a drop (50 $\mu \mathrm{L})$ of semen into a warm microscopic slide covered by a cover slip. The presence of sperm agglutination with shaky sperm head was suggestive of the existence of an immunological cause of infertility .The extent of agglutination was important. The presence of only a few groups of small numbers of agglutinated spermatozoa was also recorded. Sperm agglutination and interaction between spermatozoa were graded as:

$$
\begin{aligned}
& \text { + (Sub-mild sperm agglutination)-----------------------<=10\% } \\
& \text { ++ (Mild sperm agglutination)--------------------------10-20\% } \\
& \text { +++ (Marked sperm agglutination)----------------------21-40\% } \\
& \text { ++++ (Very marked agglutination)------------------------->40\% }
\end{aligned}
$$

For estimation of percentage of sperm agglutination the following formula is used:

Percentage of agglutinated sperm $=$ No. of agglutinated sperms x 100

Total number of spermatozoa

Sperm shaky head movement: was determined by the same formula applied to the above mentioned for sperm agglutination.

\section{Sperm-cervical mucus interaction}

For fertilization to take place in -vivo, the sperm must be able to get past the cervical mucus. The post coital test assesses the ability of sperm to penetrate and progress through cervical mucus. Cervical mucus is examined 2-3 hours after intercourse at the time of expected ovulation. A presence of greater than 10 - 
20 motile sperm per high power field is generally accepted as a normal post coital test. Post coital testing is a bio-assay that provides information concerning sexual function. Motility of the sperm, and the sperm -mucus interaction .A positive results implies normal semen and mucus. Poor results in an individual with normal semen parameters imply either cervical abnormality or the presence of sperm antibodies.

\section{Statistical Evaluation}

Data were analyzes within built functions within the Statistical Package for Social Science (SPSS UK Ltd, Chertey, Surrey , United Kingdom). We used student's t-test and multiple analysis of variance (MANOVA) to determine the level of statistical significance between the means and correlation test. Differences were considered statically significant at $\mathrm{P}<=0.05$.

\section{Results}

Two hundred and eight infertile couples were studied in this research. No significant differences between the age and body mass index in both groups, Table 1 . The duration of infertility was significant increased in group of patients which their semen analysis recorded sperm agglutination more than 10\% (Table 1).

Table 2: Prevalence of possible causes infertility in Yemeni infertile couples.
Table1: Data of patients involved in this study.

\begin{tabular}{|c|c|c|c|}
\hline Parameter & $\begin{array}{c}\text { Group I } \\
\text { with SA } \\
\mathbf{1} \% \\
\mathbf{n = 1 4 5}\end{array}$ & $\begin{array}{c}\text { Group II } \\
\text { with SA } \\
<\mathbf{1 0 \%} \mathbf{n}=\mathbf{6 3}\end{array}$ & $\mathbf{P}$ \\
\hline $\begin{array}{c}\text { Age } \\
\text { (years) } \pm \text { SD* }\end{array}$ & $31.7 \pm 3.6$ & $29.2 \pm 3.5$ & 0.17 \\
\hline $\begin{array}{c}\text { BMI (Kg/ } \\
\text { m2) SD* }\end{array}$ & 23.11 .2 & 23.61 .4 & 0.33 \\
\hline $\begin{array}{c}\text { Duration of } \\
\text { infertility } \\
\text { (yrs) SD* }\end{array}$ & 7.43 .8 & 6.24 .1 & 0.07 \\
\hline
\end{tabular}

\section{SD: Standard Deviation; BMI: Body Mass Index}

The seminal fluid infection was recorded as the higher percentage of causes of infertility in patients group-I in compared to patients in group-II (47.62 and 41.38\%, P 0.03, respectively). The idiopathic causes of immunological infertility still in the second place, (Table 2).

\begin{tabular}{|c|c|c|c|c|c|}
\hline \multirow{2}{*}{ Parameters } & \multicolumn{2}{|c|}{ Group I with SA $<10 \% n=145$} & \multicolumn{2}{|c|}{ Group II with SA $>10 \% n=63$} & \multirow{2}{*}{$\mathbf{P}$} \\
\hline & Number of Cases & $\%$ & Number of Cases & $\%$ & \\
\hline $\begin{array}{l}\text { Sterile seminal } \\
\text { fluid infection, } \\
\text { (\%). }\end{array}$ & 60 & 41.38 & 30 & 47.62 & 0.03 \\
\hline Idiopathic, (\%). & 26 & 17.93 & 19 & 30.16 & 0.02 \\
\hline Varecocele, (\%). & 18 & 12.41 & 2 & 3.17 & 0.003 \\
\hline $\begin{array}{l}\text { Orchitis } \\
\text { (unknown } \\
\text { causes), (\%) }\end{array}$ & 12 & 8.28 & 1 & 1.59 & 0.04 \\
\hline $\begin{array}{l}\text { Orchitis due to } \\
\text { mumps, (\%) }\end{array}$ & 11 & 7.59 & 0 & 0 & 0.13 \\
\hline $\begin{array}{c}\text { Surgical } \\
\text { intervention, (\%). }\end{array}$ & 11 & 7.59 & 8 & 12.7 & 0.001 \\
\hline $\begin{array}{c}\text { Accidental } \\
\text { testicular trauma, } \\
(\%)\end{array}$ & 7 & 4.83 & 3 & 4.76 & 0.001 \\
\hline Total & 145 & 100 & 63 & 100 & 0.02 \\
\hline
\end{tabular}


According to the age factor, the Figure 1 demonstrates that sperm agglutination was noted significantly $(\mathrm{P}=0.002)$ higher in age group 2 (30-40 years) compared to age group 1 and 3. Percentage of sperm shaky head movement was significantly, $\mathrm{P}=0.03$, in the age group 3 compared to age group 2 and 1 , (Figure 1).

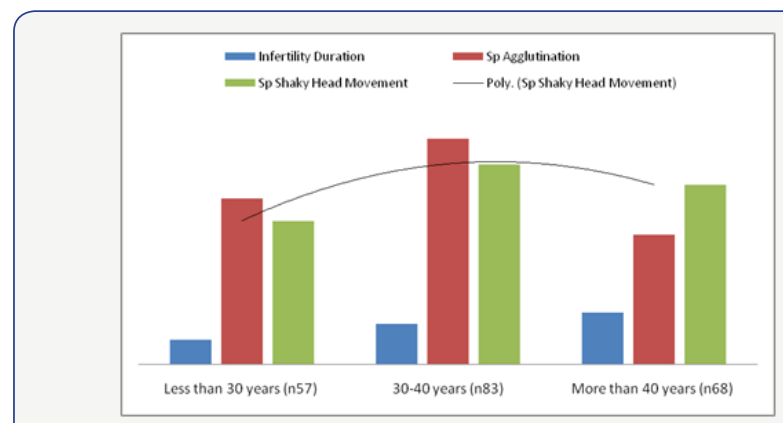

Figure 1: Grouping of patients according to the age factor.

The results of sperm cervical interaction are demonstrated in Figure 2. The percentage of motility of sperm recovery was significantly better in age group 2 compared to age groups 1 and 3 . At the same time the heist sperm concentration recovery as well as sperm agglutination were significantly $(p=0.02)$ higher in age group 2 . While percentage of recovery sperm shaky head movement was recorded in age group 3 , Figure 2, $\mathrm{P}=0.004$, compared to age group 1 and 2.

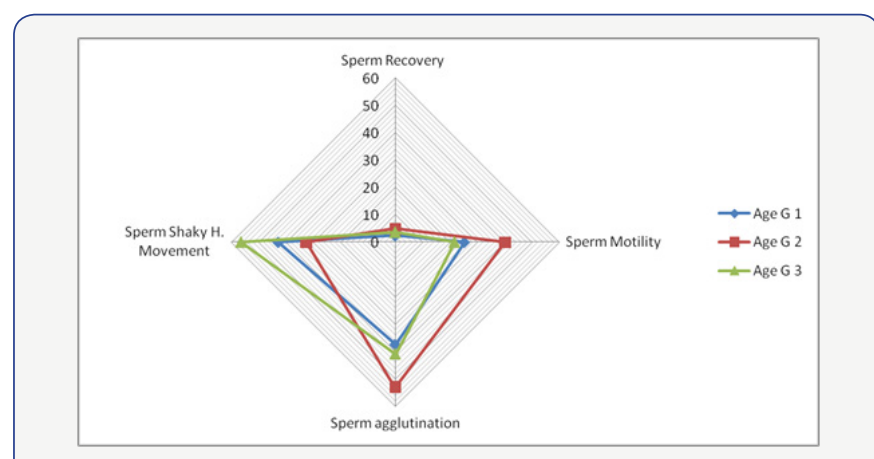

Figure 2: Sperm-Cervical Mucus Interaction.

\section{Discussion}

Two hundred and eight infertile couples were involved in this study to find the common causes of immunological infertility. It was found out that more than $60 \%$ of patients involved in the present study suffered from sterile seminal fluid infection who have a positive concentration of ASA in own sera. These results were in good agreement with that reported by Rusz et al. [10].

Presence of sterile seminal fluid infection (i.e no bacterial growth after culturing of ejaculate) or previous orchitis lead to damage of blood-testis barrier (BTB). Physiologically, the BTB is a tight junction between Sertoli cells and appears to play a major role in keeping the developing spermatozoa and immune system separate. It prevents those testicular cells expressing "foreign" antigens from coming into contact with lymphoid tissue and immunocompetent cells from entering the seminiferous tubules [11]. However, the BTB is commonly breached by physiological leakage of normally sequestered sperm antigens.

When the BTB were damaged due to infection these antigens come into contact with immunocompetent cells, ASA formation occurs and lead to formation of auto-immunity against own sperms [12]. Bronson [13] reported that the active local immunoregulatory mechanisms start being operative within the testes. Autoimmunity to sperm may occur because sperm cells antigens are first expressed during sexual maturation [14], long after the prenatal period when immunological self-tolerance is induced $[7,15,16]$.

Generally, every breakdown of blood-testis barrier and protective immunomodulatory mechanisms or hormonal immune response such as ASA formation can be induced primarily during infectious and noninfectious inflammations lead to immunoinfertility, or by obstruction of testicular efferent duct- obstructive azoospermia [12]. The ASAs were also induced after accidental and /or surgical injury of testicles, exposure to very low temperature or cryptorchidism $[17,18]$. Subsequently, infertility can result from antibodies directly binding the sperm, or from spermatogenesis due to orchitis. A similar phenomenon occurs in vasectomized laboratory rodents and man [17].

Most affected individuals developed epididymal sperm granulomas and testicular degeneration associated with the formation of ASAs. Mechanisms that can provide the autoimmunity and ASA production are micro-environmental acceleration of T-helper-type-1 (Th1) of immunity, enhanced secretion of pro-inflammatory cytokines like IL-1, reduced secretion of anti-inflammatory cytokines like IL-10 and TGF-_, up-regulation of MHC and co-stimulatory molecules expression and down-regulation of immune cells apoptotic mechanism [17]. Finally, the presence of sperm agglutination $>10 \%$ of viable sperms without bacterial seminal fluid infection and high concentration of serum ASAs reacting with antigens on the sperm are considered typical and specific immunological infertility [19].

The indication for ASAs testing in these infertile patients was abnormal semen parameters which include high percentage of SA, SSM, poor sperm motility and poor sperm mucous interaction tests (postcoital test). All these tests were strongly and significantly higher in group-I when compared to groupII. These sperm parameters were also positively correlated significantly with high concentration of their own sera ASAs and poor sperm mucous interaction tests of their wives. In the last decade there are a lot of reports on human ASAs and interference of some of them with reproductive physiology. It is supposed that sterile seminal fluid infection and high percentage of SA associating with high concentration of ASAs and binding to sperm surface which inhibit sperm function parameters and fertilization and the presence of circulating ASAs in uterine 
cervix of women have been implicated as a contributing factor to immunological infertility [6]. In these studies, the incidence of subsequent pregnancy in infertile couples was absent if one or both partners had ASAs in serum [20] or in genital tract secretions [21]. According to other reports, the prevalence of ASA positive cases in men and women with unexplained infertility was significantly more than cases with explained infertility. This certifies that ASAs affect fertility [22] and this relationship had been confirmed in our present work.

Regarding the aforementioned studies, the concept of ASAs in fertilization is based on their presence in serum and different secretions of the human reproductive tract [23]. Although some studies have pointed to the higher prevalence of ASAs in infertile patients [1]. Recently, it was successfully recommended the using of phage display technology to obtain antisperm scFv antibodies of defined antigen specificity. These antibodies will find clinical applications in the development of novel immunocontraceptives, and specific diagnostic for immunological infertility [24].

The positive correlations between percentages of sperm agglutination as well as shaky head movement and ASAs titers indicated that sperm agglutination and sperm shaky head movement should be used as a good and simple lab tests indicators for the presence of ASAs in the own sera and seminal plasma as well as good indicator for diagnosis of immunological infertility. Ability to diagnose carefully will lead to right way of treatment. Finally, using of these lab test techniques is useful, answerable and acceptable methods for diagnosis of immunological infertility [25].

Our study does not agree with the result presented by Karimi et al. [2] for the following reasons:

1. The group of patients involved in their study had unexplained infertility and such group of patients have to be infertile with unknown causes.

2. The researchers did not present any data about their spermogram including sperm agglutination, sperm shaky head movement, etc. It is our belief that such groups of unexplained infertility are a matter involving divine powers and keeping them unexplained infertile. Such group should not be subject to experimentation. Probably, for these reason the authors did not find any significant differences. That is true because it is unexplained infertility. It is our belief that the cases of such group (unexplained infertility) are unexplainable and fall in the domain of divinity.

\section{Conclusion and Recommendation}

We concluded that:

a. $60 \%$ of causes of immunological infertility mainly associated with sterile seminal fluid infection.

b. We emphasized on the importance of percentage of sperm agglutination and sperm shaky head movement should be associated with high titer of ASAs in their sera and seminal plasma.

c. The recovery of sperm-cervical We recommend the use of these so simple useful, accessible, and reliable lab tests as a routine investigation for diagnosis of high titer of ASAs as well as immunological infertility and should be considered seriously.

d. We advise that such tests should be involved in medical reports regarding infertility and expect that the authorities concerned in the ministry of health will put into effect all our suggestions and help to diagnose of immunological infertility.

\section{Acknowledgement}

First of all, authors would like to thank all workers in Allow IVF Center, Sana'a Yemen for support and permission to use their data for publication of this work. At the same time authors would like to thank the Faculty of Medicine and Health Sciences for getting ethical approval for this work.

\section{Funding}

For analysis and publication. Research Initiative Grant Scheme (RIGS-15-083-0083).

\section{References}

1. Berek, Novak (2007) Immunology and infertility. (14 $4^{\text {th }}$ edn), Lippincott Williams \& Wilkins, USA, p. 235.

2. Karimi F, Khazaei S, Alaedini F (2008) Serum antisperm antibodies in fertile and infertile individuals. IJMS 33(2): 88-93.

3. Rumke P (1954) The presence of antisperm antibodies in the serum of two patients with oligospermia. Vox Sang 4: 135-140.

4. Wilson L (1954) Sperm agglutination in human semen and blood. Exp Biol Med 85(4): 625-655.

5. Marshburn PB (1997) Antisperm antibodies and infertility. Infertility and Reproductive Medicine. Clinics of North America 18(2): 243-266.

6. Allow AK (1999) Treatment and in vitro sperm activation for immunologically infertile patients. University of Kufa, College of Medicine, Iraq, p. 236.

7. Koide SS, Kamada M (2000) Antisperm antibodies associated with infertility: properties and encoding genes of target antigens. Proc Soc Exp Biol Med 224(4): 123-132.

8. Tain X, Wu y, Yang C, Liu p (1999) Relationship between serum antisperm antibodies and anticardiolipin antibodies and clinical pregnancy outcome in an in vitro fertilization and embryo transfer program. Chinese Medical Journal 112(1): 34-36.

9. World Health Organization (WHO) (2010) Laboratory manual for the examination of human semen and sperm cervical mucus interaction. $\left(5^{\text {th }}\right.$ edn), Volume 4, Cambridge University Press, New York, USA, p. 4-59.

10. Rusz A, Pilatz F, Wagenlehner T, Linn Th, Diemer HC, et al. (2012) Influence of urogenital infections and inflammation on semen quality and male fertility. World J Urol 30(1): 23-30.

11. Omu AE, Al-Othman S, Mohamad AS, Al-Kalnwby NM, Fernandes S (1998) Antibiotic Therapy for Seminal Infection Effect on Antioxidant 
Activity and T-Helper Cytokines. J Reprod Med 43(10): 857-864.

12. Almagor M, Dan- Goor M, Hovav Y, Kafka I (1998) Antisperm antibodies in men with psychogenic anejaculation. Arch Androl 41(1): 1-4.

13. Bronson R (1999) Detection of antisperm antibodies: an argument against therapeutic nihilism. Hum Reprod 14(7): 1671-1673.

14. Allow AK (2002) The efficinacy of antisperm antibody separation (ASAS) and anintrauterine insemination in couples with immunologic infertility. Annals of College of Medicine Mousel 28: 36-41.

15. Lombardo F, Lenzi A, Dondero F (2004) Antisperm immunity in assisted reproduction. J of Reprod Immunol 62(1-2): 101-109.

16. Naz RK, Menge RC (1994) Antisperm antibodies: origin, regulation and sperm activity in human infertility. Fertile Steril 61(6): 10011013.

17. McDonald SW (2000) Cellular responses to vasectomy. Int Rev Cytol 199: 295-339.

18. Fábio F, Lucon H, Plínio M, Góes B, Saldanha S (2003) Induction of spermatogenesis in azoospermic men after varicocele repair. Hum Reprod 18(1): 108-112.

19. Allow AK (2001) The effect of three courses of treatment with antibiotic and prednisolone on sperm agglutination and sperm morphology in immunologically infertile patients. Kufa Medical J 4: 392-399.

20. Cibulka J, Balvin M, Bibková K, Micanová Z (2009) Isolation and immunology identification of spermagglutinating antibodies from human serum. Ceska Gynekol 74(3): 201-208.

21. Emin A, Lichev D, Avazova N, Popov I, Radev R (2008) The importance of the presence of antisperm antibodies in serum and ejaculate of men with infertility. Akush Ginekol ( Sofiia) 47(2): 26-30.

22. Ulcova-Gallova Z, Vrzalova J, Bibkova K, Peknicova J, Micanova Z, et al. (2009) Sperm antibodies, intraacrosomal sperm proteins, and cytokines in semen in men from infertile couples. Am J ReprodImmunol 61(3): 236-245.

23. Berkowitz RS, Ryan KBR, J Kistner RW (1995) Principles and Practice. Mosby- Year Book, (6 $6^{\text {th }}$ edn).

24. Samuel AS, Naz RK (2008) Isolation of human single chain variable fragment antibodies against specific sperm antigens for immunocontraceptive development. Hum Repr 23(6): 1324-1337.

25. Bubanovic I, Najman S, Kojic S (2004) Immunomodulatory Treatment for Infertile Men with Antisperm Antibodies. Fertile Steril 81(3): S7S31.

\section{Your next submission with Juniper Publishers will reach you the below assets}

- Quality Editorial service

- Swift Peer Review

- Reprints availability

- E-prints Service

- Manuscript Podcast for convenient understanding

- Global attainment for your research

- Manuscript accessibility in different formats

( Pdf, E-pub, Full Text, Audio)

- Unceasing customer service

Track the below URL for one-step submission https://juniperpublishers.com/online-submission.php 